\title{
Risk factors associated with 1-year mortality among patients with HIV-associated tuberculosis in areas with intermediate tuberculosis burden and low HIV prevalence
}

\author{
CK Chan *, KH Wong, MP Lee, Kenny CW Chan, CC Leung, Eric CC Leung, WK Chan, Ida KY Mak
}

This article was published on 28 Sep 2018 at www.hkmj.org.

\section{A B S T R A C T}

Introduction: Data are limited regarding risk factors for mortality among patients with human immunodeficiency virus (HIV)-associated tuberculosis (TB) in areas with low HIV prevalence and intermediate TB burden, such as the Western Pacific region. This study aimed to assess such risk factors in Hong Kong, which has an intermediate TB burden and low HIV prevalence.

Methods: We conducted a retrospective cohort analysis of adult patients reported to the Hong Kong TB-HIV Registry between 2006 and 2015. Baseline characteristics were compared with Kaplan-Meier estimates. Cox proportional hazards regression modelling was used to identify factors associated with mortality.

Results: Of 299 patients studied, 21 (7.0\%) died within 12 months of anti-TB treatment (median [interquartile range], 7.5 [3.8-10] months). The median age of death was 54 (interquartile range, 40.5-75.0) years. The cause of death was TB in five and unrelated to TB in the remaining 16. Cox proportional hazards regression showed that older age (adjusted hazard ratio $=4.5 ; 95 \%$ confidence interval $[\mathrm{CI}]=1.4-14.9)$, history of drug addiction (4.6; 95\% CI=1.6-13.0), and low baseline CD4 cell count of $<50 / \mu \mathrm{L}(2.9 ; 95 \% \mathrm{CI}=1.1-7.7)$ were independent risk factors for death within 12 months.
Conclusion: This study complements previous studies by providing information regarding risk factors associated with mortality among patients with HIV-associated TB in areas with intermediate TB burden and low HIV prevalence. The results from our study may guide targeted measures to improve survival in other areas with intermediate TB burden and low HIV prevalence, such as the Western Pacific region.

Hong Kong Med J 2018;24:473-83

DOI: 10.12809/hkmj187303

${ }^{1}$ CK Chan *, FHKCP, FHKAM (Medicine)

${ }^{2} \mathrm{KH}$ Wong, FHKCP, FHKAM (Medicine)

${ }^{3}$ MP Lee, FHKCP, FHKAM (Medicine)

${ }^{4}$ KCW Chan, FHKCP, FHKAM (Medicine)

${ }^{1}$ CC Leung, FHKCP, FHKAM (Medicine)

${ }^{1}$ ECC Leung, FHKCP, FHKAM (Medicine)

${ }^{4}$ WK Chan, BNurs (Hons), MNurs

${ }^{1}$ IKY Mak, BSc, MPhil

Tuberculosis and Chest Service, Centre for Health Protection, Department of Health, Hong Kong

Head Office, Centre for Health Protection, Department of Health, Hong Kong

Department of Medicine, Queen Elizabeth Hospital, Hospital Authority, Hong Kong

${ }^{4}$ Integrated Treatment Centre, Special Preventive Programme, Centre for Health Protection, Department of Health, Hong Kong

* Corresponding author: chikuen_chan@dh.gov.hk

New knowledge added by this study

- Previous studies on risk factors associated with mortality among patients with human immunodeficiency virus (HIV)-associated tuberculosis (TB) have mainly examined patients from developing countries with high TB burden and high HIV prevalence, especially from Africa.

- The present study showed that older age, a history of drug addiction, and a low baseline CD4 cell count of $<50 / \mu \mathrm{L}$ were independent risk factors for death within 12 months in an area with intermediate TB burden, low HIV prevalence, and good infrastructure.

Implications for clinical practice or policy

- This study might facilitate formulation of innovative strategies to improve health outcomes among patients with HIV-associated TB in areas with intermediate TB burden and low HIV prevalence.

\section{Introduction}

In 2016, there were an estimated 10.4 million new tuberculosis (TB) cases worldwide, of which 1.03 million (10\%) were among people living with human immunodeficiency virus (HIV). ${ }^{1}$ Of the estimated
1.7 million deaths resulting from $\mathrm{TB}$ disease, 0.4 million were among people living with HIV. ${ }^{1}$ The success rate of $\mathrm{TB}$ treatment is generally worse for patients with HIV than for those without. Globally, the proportion of patients with TB who died during 


\section{愛滋病毒感染率低及結核病中度負擔地區有關人 類免疫缺乏病毒合併結核病一年內死亡風險因素 \\ 陳志權、黄加慶、李文寶、陳志偉、梁子超、梁中正、 陳惠結、麥家欣}

引言：在一些愛滋病毒感染率低結核病中度負擔地區如西太平洋區， 有關人類免疫缺乏病毒 (HIV) 合併結核病 (TB ) 死亡風險因素的數 據不多。作為屬結核病中度負擔及愛滋病毒感染率低地區, 本研究旨 在評估香港在這方面的風險因素。

方法：我們進行一項2006年至2015年期間全港TB-HIV資料庫內成年 病人的回顧性隊列研究。以Kaplan-Meier函數比較基線特徵, 及Cox 比例風險迴歸模型應用分辨死亡風險因素。

結果：在 299 名研究病人當中, 21 人 $(7.0 \%)$ 於結核病治療 12 個月內 死亡（中位數 7.5 個月, 四分間距3.8-10個月）。死亡年齡中位數是 54歲（四分間距40.5-75.0歲）。5宗病例的死因為結核病, 其餘16宗 死於非結核病。Cox比例風險迴歸分析顯示年齡較大（調整後風險比 值 $4.5 ； 95 \%$ 置信區間 1.4-14.9）、曾濫用藥物（調整後風險比值4.6 ; 95\%置信區間 1.6-13.0）及基線CD4值低於 $<50 / \mu \mathrm{L}$ （調整後風險比 值 $2.9 ； 95 \%$ 置信區間 1.1-7.7）的患者是 12 個月內死亡的獨立風險因 素。

結論：這項研究為早前研究補充了結核病中度負擔及愛滋病毒感染率 低地區有關HIV合併TB死亡風險因素的數據, 有助結核病中度負擔及 愛滋病毒感染率低地區如西太平洋區制定針對性措施, 提高病人存活 率。 years. ${ }^{9}$ The overall TB mortality rate was 2.3 per 100000 population in the same year. The prevalence of HIV infection in the general population in Hong Kong is low $(<0.1 \%) .{ }^{10}$ Notably, patients with HIVassociated TB constituted approximately $1 \%$ of all TB notifications in Hong Kong. ${ }^{9}$ Treatment outcomes of a cohort of patients reported to the territory-wide TB-HIV Registry of the Hong Kong Department of Health, as of 31 December 2009, have been reported previously. ${ }^{11}$ The aim of the present study was to assess the 1-year mortality rate among patients with HIV-associated TB and to identify risk factors associated with mortality. Therefore, we retrospectively reviewed the data of patients reported to the TB-HIV Registry between 1 January 2006 and 31 December 2015. The results of this study are expected to guide targeted measures to improve survival and to inform TB control policies in areas with intermediate TB burden, such in Hong Kong and throughout the Western Pacific region.

\section{Methods}

Data regarding sex, age, ethnicity, case category, history of drug addiction, site of TB infection, sputum smear and culture results, CD4 cell count at TB diagnosis, and ART usage of consecutive patients reported to the TB-HIV Registry between 1 January 2006 and 31 December 2015 were retrieved and retrospectively reviewed. Tuberculosis treatment outcomes at 12 months after initiation of treatment, and mortality data such as the date and cause(s) of death, were obtained from the database. Further mortality data were obtained by cross-matching with the statutory death registry by using patients' identity card numbers/passport numbers as unique identifiers. For patients who died within 12 months during anti-TB treatment, relevant clinical records from chest clinics and hospitals were traced and reviewed.

All the data collected were imported into Epi-Info software, and exported into SPSS (Windows version 16.0; SPSS Inc, Chicago [IL], US) for analysis. For the identification of variables potentially associated with mortality, comparisons of survival status were made by using Kaplan-Meier estimates. A two-tailed P value $<0.05$ was considered statistically significant. An evaluation of the effects of covariates on mortality was performed by using Cox proportional hazards regression modelling. Variables that were significant in the univariate analysis or were of clinical significance were included in the model. Patients who had been transferred out of Hong Kong before completion of treatment were censored at the date they were last known to be alive, based on the date of their most recent contact. For patients who were lost to follow-up, but were not deceased according to the statutory death registry, the censor date was 12 months. Kaplan-Meier 
survival curves were generated to demonstrate differences in mortality, stratified for a variety of covariates.

\section{Results}

Of 337 patients reported to the TB-HIV Registry between 2006 and 2015, 17 were excluded either because of duplicate reporting or revision of diagnosis. Twenty-one patients were tourists or illegal immigrants with a very short stay in Hong Kong; these were also excluded, resulting in 299 patients in the analysis. Baseline demographic and clinical characteristics of these 299 patients, stratified by survival status at 12 months from the date of start of anti-TB treatment, are shown in Table 1. Overall, extrapulmonary TB was common, present in approximately $65 \%$ of patients. Sputum smear positivity was present in more than one-third of patients. Of note, the multidrug resistance rate among the bacteriologically proven cases was low (2.2\% overall). The overall median CD4 cell count at the time of TB diagnosis was $100 / \mu \mathrm{L}$ (interquartile range [IQR], 36-204/ $\mu \mathrm{L}$ ). Of 284 patients who were alive and had not defaulted or transferred out at 8 weeks from the initiation of TB treatment, 73 (25.7\%) were undergoing ART. The proportion undergoing ART at 8 weeks was higher among patients reported to the TB-HIV Registry between 2011 and 2015 than among those reported between 2006 and 2010 (37.3\% vs $18.4 \%$; $\mathrm{P}=0.0005)$.

Overall, 135 (45.2\%) were cured or had completed treatment at 12 months, whereas 96 (32.1\%) remained on an anti-TB treatment regimen at 12 months due to extensive disease, use of a nonstandard treatment regimen, and/or drug resistance. Twenty-three $(7.7 \%)$ patients defaulted treatment for more than 2 months, while 24 (8.0\%) patients were transferred out; 21 (7.0\%) patients died within 12 months of the initiation of anti-TB treatment. The proportions of patients who died within 12 months among patients reported to the TB-HIV Registry between 2011 and 2015 and those reported between 2006 and 2010 were similar (7.1\% vs 6.9\%). The median time interval between the initiation of anti-TB treatment and death was 7.5 months (IQR, 3.8-10 months); the median age of death was 54 (IQR, 40.5-75.0) years. The cause of death was due to $\mathrm{TB}$ in five patients and unrelated to $\mathrm{TB}$ in the remaining 16 (Table 2). A similar proportion of patients with early death within 2 months died from TB (25.0\%), compared with those who died after 2 months (23.5\%; $\mathrm{P}=0.72$ ).

Table 3 summarises the results of univariate (using Kaplan-Meier estimates) and Cox proportional hazards regression analysis with respect to 1-year mortality of the 299 cases. In the univariate analysis, older age, case categories other than new cases, a positive sputum smear, a history of drug addiction, and a low CD4 cell count $(<50 / \mu \mathrm{L})$ at the time of TB diagnosis were associated with mortality. Further analysis with Cox proportional hazards regression showed that older age (adjusted hazard ratio $=4.5$; 95\% confidence interval $[\mathrm{CI}]=1.4-14.9 ; \mathrm{P}=0.012)$, a history of drug addiction (adjusted hazard ratio $=4.6$; 95\% $\mathrm{CI}=1.6-13.0 ; \mathrm{P}=0.005)$ and a low $\mathrm{CD} 4$ cell count $(<50 / \mu \mathrm{L})$ at the time of TB diagnosis (adjusted hazard ratio $=2.9 ; 95 \% \mathrm{CI}=1.1-7.7 ; \mathrm{P}=0.03)$ remained the sole independent risk factors for death within 12 months. Similar findings were observed when ART at 8 weeks was included in the Cox proportional hazards regression model (results not shown). Unadjusted Kaplan-Meier survival curves stratified by covariates are shown in the Figure.

\section{Discussion}

This retrospective cohort study was designed to examine the mortality pattern and factors associated with 1-year mortality among patients with HIVassociated TB reported to the Hong Kong TB-HIV Registry. In our cohort, $7.0 \%$ died within 12 months of anti-TB treatment (median [IQR], 7.5 months [3.8-10 months]). The median age of death was 54 (IQR, 40.5-75.0) years. The cause of death was unrelated to TB in $>75 \%$ of the cohort. Older age, history of drug addiction, and a low CD4 cell count $(<50 / \mu \mathrm{L})$ at the time of TB diagnosis were independent risk factors for death within 12 months.

The 1-year mortality rate of $7.0 \%$ among patients with HIV-associated TB in our cohort was lower than the rates in Eastern Europe (29\%) and Latin America (11\%) reported in a study by Podlekareva et al. ${ }^{2}$ The mortality rate in our study was also lower than the rates reported in other countries in the Western Pacific region, such as Thailand $(17 \%)^{7}$ and Cambodia $(22.5 \%)^{8}$ among enrolled patients with HIV-associated TB. Nonetheless, the rate was higher than the $4 \%$ reported for Western Europe. ${ }^{2}$ Although these rates might not be directly comparable because of differences in the study periods and methodologies used, the results from our study add important data to the current body of literature regarding mortality risk among patients with HIV-associated TB in the Western Pacific region.

In our cohort, $76.2 \%$ of deaths were unrelated to TB. This differed from the proportion reported among patients with HIV-associated TB in Eastern Europe; TB was reported as the cause of death in $>60 \%$ of those who died. ${ }^{2}$ Differences in patient profile, degree of immunosuppression, proportion of patients receiving ART, and proportion of patients with other opportunistic infections might have contributed to the differences observed with respect to the cause(s) of death.

The proportion of patients who died within the first 2 months of anti-TB treatment due to TB was similar to that among patients who died after 2 
TABLE I. Demographic and clinical characteristics of patients reported to the Hong Kong TB-HIV Registry between 2006 and 2015 , stratified by survival status at 12 months from the start of anti-TB treatment*

\begin{tabular}{|c|c|c|c|c|}
\hline & \multicolumn{2}{|c|}{ Survival status at 12 months } & \multirow[t]{2}{*}{ Total $(n=299)$} & \multirow[t]{2}{*}{$P$ value } \\
\hline & Alive $(n=278)$ & Dead $(n=21)$ & & \\
\hline Reporting period & & & & 0.988 \\
\hline $2006-2010$ & $170(61.2)$ & $13(61.9)$ & $183(61.2)$ & \\
\hline $2011-2015$ & $108(38.8)$ & $8(38.1)$ & $116(38.8)$ & \\
\hline Age-group (years) & & & & $<0.001$ \\
\hline $15-44$ & $162(58.3)$ & $6(28.6)$ & $168(56.2)$ & \\
\hline $45-64$ & $93(33.5)$ & $8(38.1)$ & $101(33.8)$ & \\
\hline$\geq 65$ & $23(8.3)$ & $7(33.3)$ & $30(10.0)$ & \\
\hline Gender & & & & 0.153 \\
\hline Male & $229(82.4)$ & $20(95.2)$ & 249 (83.3) & \\
\hline Female & 49 (17.6) & $1(4.8)$ & $50(16.7)$ & \\
\hline Ethnicity & & & & 0.324 \\
\hline Chinese & $188(67.6)$ & $17(81.0)$ & $205(68.6)$ & \\
\hline Asian (non-Chinese) & $76(27.3)$ & $4(19.0)$ & $80(26.8)$ & \\
\hline African & $13(4.7)$ & 0 & $13(4.3)$ & \\
\hline Other & $1(0.4)$ & 0 & $1(0.3)$ & \\
\hline Case category & & & & 0.005 \\
\hline New & $251(90.3)$ & $14(66.7)$ & $265(88.6)$ & \\
\hline Relapse & $18(6.5)$ & $5(23.8)$ & $23(7.7)$ & \\
\hline Treatment after default & $7(2.5)$ & $1(4.8)$ & $8(2.7)$ & \\
\hline Other & $2(0.7)$ & 0 & $2(0.7)$ & \\
\hline Unknown & 0 & $1(4.8)$ & $1(0.3)$ & \\
\hline History of drug addiction & & & & 0.011 \\
\hline Yes & $32(11.5)$ & $6(28.6)$ & $38(12.7)$ & \\
\hline No & $222(79.9)$ & $13(61.9)$ & $235(78.6)$ & \\
\hline Unknown & $24(8.6)$ & $2(9.5)$ & $26(8.7)$ & \\
\hline Underlying medical illness(es) & $44(15.8)$ & $3(14.3)$ & $47(15.7)$ & 0.466 \\
\hline Diabetes mellitus & $16(5.8)$ & 0 & $16(5.4)$ & \\
\hline Malignancy & $9(3.2)$ & 0 & $9(3.0)$ & \\
\hline Chronic renal disease & $11(4.0)$ & $1(4.8)$ & $12(4.0)$ & \\
\hline $\begin{array}{l}\text { Other immunocompromised status (eg, alcoholic, corticosteroid use, } \\
\text { general debilitation, pneumoconiosis) }\end{array}$ & $12(4.3)$ & $2(9.5)$ & $14(4.7)$ & \\
\hline Mode of diagnosis & & & & 0.129 \\
\hline Bacteriological $†$ & $152(54.7)$ & $15(71.4)$ & $167(55.9)$ & \\
\hline Histological & $66(23.7)$ & $2(9.5)$ & $68(22.7)$ & \\
\hline Radiological & $43(15.5)$ & $3(14.3)$ & $46(15.4)$ & \\
\hline Clinical & $3(1.1)$ & 0 & $3(1.0)$ & \\
\hline Unknown & $14(5.0)$ & $1(4.8)$ & $15(5.0)$ & \\
\hline Extrapulmonary involvement & & & & 0.378 \\
\hline Yes & $182(65.5)$ & $12(57.1)$ & 194 (64.9) & \\
\hline No & 96 (34.5) & 9 (42.9) & 105 & \\
\hline
\end{tabular}

Abbreviations: $\mathrm{AIDS}=$ acquired immunodeficiency syndrome; $\mathrm{ART}=$ antiretroviral therapy; $\mathrm{HIV}=$ human immunodeficiency virus; $\mathrm{MDR}=$ multidrug resistance; $\mathrm{TB}=$ tuberculosis; $\mathrm{XDR}=$ extensive drug resistance

* Data are shown as No. (\%)

† Bacteriological diagnosis refers to a diagnosis of TB based on a positive sputum smear, a positive culture for Mycobacterium tuberculosis organisms in sputum or other specimens, or a positive $M$ tuberculosis polymerase chain reaction for the more recent cases 


\begin{tabular}{|c|c|c|c|c|}
\hline & \multicolumn{2}{|c|}{ Survival status at 12 months } & \multirow[t]{2}{*}{ Total $(n=299)$} & \multirow[t]{2}{*}{$P$ value } \\
\hline & Alive $(n=278)$ & Dead $(n=21)$ & & \\
\hline Extent of lung parenchymal lesions $(n=227)$ & & & & 0.190 \\
\hline Less than the equivalent of a right upper lobe & $103(49.3)$ & $6(33.3)$ & $109(48.0)$ & \\
\hline $\begin{array}{l}\text { More than the equivalent of a right upper lobe but less than the } \\
\text { right lung }\end{array}$ & $51(24.4)$ & $5(27.8)$ & $56(24.7)$ & \\
\hline More than the equivalent of right lung & $55(26.3)$ & 7 (38.9) & $62(27.3)$ & \\
\hline \multicolumn{5}{|l|}{ Bacteriological data } \\
\hline Positive sputum smear & $96(34.5)$ & $12(57.1)$ & $108(36.1)$ & 0.041 \\
\hline Positive sputum and/or other cultures & $205(73.7)$ & $19(90.5)$ & $224(74.9)$ & 0.066 \\
\hline No resistance & $163(79.5)$ & $16(84.2)$ & $179(79.9)$ & 0.621 \\
\hline Any resistance (other than MDR/XDR) & $39(19.0)$ & $1(5.3)$ & $40(17.9)$ & \\
\hline MDR & $3(1.5)$ & $2(10.5)$ & $5(2.2)$ & \\
\hline XDR & 0 & 0 & 0 & \\
\hline CD4 cell count at TB diagnosis (cells $/ \mu \mathrm{L}$ ) & & & & 0.022 \\
\hline$<50$ & $75(27.0)$ & $10(47.6)$ & $85(28.4)$ & \\
\hline $50-199$ & $92(33.1)$ & $6(28.6)$ & $98(32.8)$ & \\
\hline$\geq 200$ & $61(21.9)$ & $1(4.8)$ & $62(20.7)$ & \\
\hline Unknown & $50(18.0)$ & $4(19.0)$ & $54(18.1)$ & \\
\hline TB as an AIDS-defining illness & & & & 0.441 \\
\hline Yes & $167(60.1)$ & $11(52.4)$ & $178(59.5)$ & \\
\hline No & $71(25.5)$ & 7 (33.3) & $78(26.1)$ & \\
\hline Unknown & $40(14.4)$ & $3(14.3)$ & $43(14.4)$ & \\
\hline ART at 8 weeks $(n=284)$ & & & & 0.484 \\
\hline Yes & $69(25.8)$ & $4(23.5)$ & $73(25.7)$ & \\
\hline No & 198 (74.2) & $13(76.5)$ & 211 (74.3) & \\
\hline
\end{tabular}

months (25.0\% vs $23.5 \%)$. This finding differed from the outcome of a prospective observational study that examined the causes of death among patients with HIV-associated TB in Thailand: 18 of 33 deaths (55\%) within 60 days after initiation of TB treatment were caused by TB, compared with 11 of 41 deaths (27\%) beyond 60 days after initiation of TB treatment $(\mathrm{P}=0.02){ }^{7}$ However, the patients in that study exhibited a greater degree of immunosuppression: the median CD4 count for patients in that study was $55 / \mu \mathrm{L}$ (IQR, 18-142/ $\mu \mathrm{L}$ ), compared with a median CD4 count of $100 / \mu \mathrm{L}$ (IQR, 36-204/ $\mu \mathrm{L}$ ) in our cohort.

The finding that older age constitutes a risk factor for mortality in our cohort is consistent with findings in some other studies., ${ }^{4,5,12}$ In a recently reported retrospective 10-year electronic record review of patients with TB in a South African province, although the large majority of patients with TB that died were aged 18 to 49 years, the odds of dying were incrementally higher in older age-groups: 8 to 17 years (adjusted odds ratio $[\mathrm{AOR}]=2.0$; 95\% CI $=1.5$ -
$2.7), 18$ to 49 years $(\mathrm{AOR}=5.8 ; 95 \% \mathrm{CI}=4.0-8.4), 50$ to 64 years $(A O R=7.7 ; 95 \% C I=4.6-12.7)$, and $\geq 65$ years ( $\mathrm{AOR}=14.4 ; 95 \% \mathrm{CI}=10.3-20.2) .{ }^{4}$ A similar finding was observed in another South African study. ${ }^{5}$ In our cohort, the median age of death was 54 years. Patients aged $\geq 65$ years had an adjusted hazard ratio of 4.5 for dying, compared with younger patients. Atypical presentation, increased comorbidity, and a higher proportion of drug-related adverse events might have contributed to the increased odds of death in the older age-group.

In our cohort, a history of drug addiction was significantly associated with death at 12 months (adjusted hazard ratio $=4.6 ; 95 \% \mathrm{CI}=1.6-13.0$ ). In the study by The TB:HIV Study Writing Group, injection drug use was reported as a significant predictor of death (hazard ratio $=2.11 ; 95 \% \mathrm{CI}=1.04$ 4.26); notably, this became non-significant after adjustment due to high correlation with the region of residence. ${ }^{3}$ The association between a history of drug abuse and mortality in our cohort-also reported in some other studies-is not surprising. 
TABLE 2. Characteristics, causes, and timing of death of patients with HIV-associated TB who died within 12 months from initiation of anti-TB treatment $(n=2 I)$

\begin{tabular}{|c|c|c|c|c|c|c|}
\hline $\begin{array}{l}\text { Patient } \\
\text { No. }\end{array}$ & Sex & $\begin{array}{c}\text { Age } \\
\text { (years) }\end{array}$ & Ethnicity & Case category & Drug addiction & $\begin{array}{l}\text { CD4 cell count at TB } \\
\text { diagnosis (cells } / \mu \mathrm{L})\end{array}$ \\
\hline
\end{tabular}

\section{Early death within 2 months from initiation of anti-TB treatment}

$\begin{array}{ccccccccc}1 & \text { M } & 42 & \text { Vietnamese } & \text { Relapse } & \text { Yes } & 27 & \text { No } \\ 2 & M & 39 & \text { Chinese } & \text { Unknown } & \text { Unknown } & 9 & \text { Unknown } \\ 3 & M & 83 & \text { Chinese } & \text { New } & \text { No } & \text { Unknown }\end{array}$

4

M

47

Chinese

New

No

Unknown

No

Death after 2 months from initiation of anti-TB treatment$$
3
$$

3

56

Chinese

4

5

$\begin{array}{ll}M & 56 \\ M & 75\end{array}$

F

34

Chinese

Indonesian

Chinese

Relapse

No

116

No

6

7

8

9

M 26

$10-M$

$10 \quad M \quad 56$

$\begin{array}{ll}11 & \mathrm{M} \\ 12 & \mathrm{M}\end{array}$

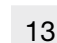

M 31

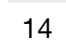

M 37

77

Chinese
Chinese
Chinese

Chinese

Chinese

31

Indonesian

37

N

$\begin{array}{ll}15 & M \\ 16 & M\end{array}$

17

$\begin{array}{ll}M & 49 \\ M & 75 \\ M & 53\end{array}$

Abbreviations: ART = antiretroviral therapy; HIV = human immunodeficiency virus; IRIS = immune reconstitution inflammatory syndrome; MTB = Mycobacterium tuberculosis; TB = tuberculosis;TBDOS = date of starting anti-TB treatment

* ART within 8 weeks or before death, whichever was earlier 
Ex-prisoner; severely immunocompromised patient; refused ART; pulmonary TB due to MTB with favourable drug susceptibility pattern

Pulmonary TB, sputum smear-negative, culture and drug susceptibility result could not be traced

Pulmonary TB due to MTB with favourable drug susceptibility pattern; underlying asbestosis, chronic obstructive pulmonary disease; treatment complicated by deranged liver function; received primarily non-standard TB regimen

Disseminated TB (lung, pleura, hilar and abdominal lymph node) due to MTB with favourable drug susceptibility pattern; treatment complicated by skin rash

\section{Pyonephrosis, sepsis}

Unspecified HIV disease

1

TB lung, pneumonia

Other ill-defined and unspecified causes of mortality

Disseminated TB (lung, lymph node, spleen) due to MTB with favourable drug susceptibility pattern, treatment complicated by IRIS (increased submandibular lymph node at 8 weeks from TBDOS), did not require TB treatment interruption

Pulmonary and abdominal TB due to MTB with favourable drug susceptibility pattern

Disseminated TB (lung, lymph node, meninges); cerebrospinal fluid culture-negative but MTB DNA-positive

Pulmonary TB, TB lymph node and miliary TB due to MTB with favourable drug susceptibility pattern

TB pleural effusion, TB supraclavicular and mediastinal lymph node due to MTB with favourable drug susceptibility pattern; treatment complicated by IRIS (low-grade fever and increased supraclavicular lymph node at 3 weeks from TBDOS), did not require TB treatment interruption

Cavitary pulmonary TB due to MTB with favourable drug susceptibility pattern; treatment complicated by deranged liver function; received primarily non-standard TB regimen

TB pleural effusion due to MTB with favourable drug susceptibility pattern; treatment complicated by skin rash; received primarily non-standard TB regimen

TB pleural effusion and TB spine due to MTB with favourable drug susceptibility pattern

Pulmonary TB, multidrug resistance (multidrug-resistant TB resistant to streptomycin, isoniazid, rifampicin; susceptible to ethambutol), initial treatment regimen consisted of prothionamide, paraamino salicylate, levofloxacin, pyrazinamide, ethambutol

Pulmonary TB due to MTB with favourable drug susceptibility pattern; underlying chronic hepatitis C; pretreatment blood test showed thrombocytopenia; poor compliance with drugs

Pulmonary TB due to MTB with favourable drug susceptibility pattern; hepatitis B surface antigen carrier

Pulmonary TB (multidrug-resistant TB resistant to streptomycin, isoniazid, rifampicin; susceptible to ethambutol), initial treatment regimen consisted of prothionamide, cycloserine, levofloxacin, pyrazinamide, ethambutol), underlying old stroke

Disseminated TB (lung, supraclavicular and retroperitoneal lymph node) due to MTB with favourable drug susceptibility pattern; chronic hepatitis B and C; treatment complicated by fever and chill

Pulmonary TB and military TB due to due to MTB with favourable drug susceptibility pattern; treatment complicated by IRIS (increased right upper zone lung shadows and prolonged fever at 6 weeks from TBDOS, requiring TB treatment interruption)

Extensive pulmonary TB due to MTB with favourable drug susceptibility pattern; chronic hepatitis C; treatment complicated by deranged liver function

Disseminated TB (lung, lymph node, meninges, genitourinary, choroid) due to MTB with favourable drug susceptibility pattern

Disseminated TB (lung, psoas abscess, genitourinary tract), bacillary resistance to streptomycin and isoniazid
Non-Hodgkin lymphoma

Peritonitis, fulminant

hepatic failure from chronic hepatitis B

TB meningitis, Klebsiella $\quad 5$
pneumonia

Myocardial infarct

8

Unspecified HIV disease

\section{TB lung}

3

Unspecified pneumonia

8.5

Pneumonia

Miliary TB, drug

overdose

Unspecified pneumonia, aspiration

TB lung

5

7.5

Sepsis

Unspecified pneumonia

Carcinoma of liver

Unspecified pneumonia

Hepatic failure

(unspecified), underlying chronic hepatitis B
Fungal septicaemia 
TABLE 3. Survival status at 12 months of 299 patients with HIV-associated TB and comparison by univariate and Cox proportional hazards regression modelling

\begin{tabular}{|c|c|c|c|c|c|c|}
\hline \multirow[t]{2}{*}{ Variable* } & \multicolumn{2}{|c|}{ Survival status at 12 months } & \multirow[t]{2}{*}{$P$ valuet } & \multicolumn{3}{|c|}{ Cox proportional hazards regression modelling } \\
\hline & Alive $(n=278)$ & Dead $(n=21)$ & & Hazard ratio & $95 \% \mathrm{Cl}$ & $P$ value \\
\hline Age-group (years) & & & $<0.001$ & & & \\
\hline$<65$ & $255(91.7 \%)$ & $14(66.7 \%)$ & & 1 & - & - \\
\hline$\geq 65$ & $23(8.3 \%)$ & $7(33.3 \%)$ & & 4.5 & $1.4-14.9$ & 0.012 \\
\hline Case category $\ddagger$ & & & 0.005 & & & \\
\hline New & $251(90.3 \%)$ & $15(71.4 \%)$ & & - & - & - \\
\hline Other & $27(9.7 \%)$ & $6(28.6 \%)$ & & - & - & - \\
\hline History of drug addiction§ & & & 0.011 & & & \\
\hline No & $246(88.5 \%)$ & $15(71.4 \%)$ & & 1 & - & - \\
\hline Yes & $32(11.5 \%)$ & $6(28.6 \%)$ & & 4.6 & $1.6-13.0$ & 0.005 \\
\hline Sputum smear & & & 0.041 & & & \\
\hline Negative/not done & $182(65.5 \%)$ & $9(42.9 \%)$ & & - & - & - \\
\hline Positive & $96(34.5 \%)$ & $12(57.1 \%)$ & & - & - & - \\
\hline CD4 cell count at TB diagnosis (cells $/ \mu \mathrm{L}) \|$ & & & 0.022 & & & \\
\hline$<50$ & $75(32.9 \%)$ & $10(58.8 \%)$ & & 2.9 & $1.1-7.7$ & 0.03 \\
\hline$\geq 50$ & $153(67.1 \%)$ & $7(41.2 \%)$ & & 1 & - & - \\
\hline
\end{tabular}

Abbreviations: 95\% Cl = 95\% confidence interval; $\mathrm{HIV}=$ human immunodeficiency virus; $\mathrm{TB}=$ tuberculosis

* Only variables that were significant in the univariate analysis in Table I were included in Cox proportional hazards regression modelling

+ Univariate analysis with Kaplan-Meier estimates

$\neq$ One $(0.3 \%)$ patient with missing information was classified as a new case

$\S 26(8.7 \%)$ Patients with missing information on history of drug addiction were classified as non-users

॥ Among 228 and 17 patients with CD4 cell count results in the alive and dead groups, respectively

Poor access to and uptake of health services, poor adherence, and treatment default are well-known to pose unique challenges for treatment of drug users. ${ }^{13}$ In a study of 291 patients with smear- and culturepositive pulmonary TB presenting for retreatment in Morocco, substance users were 2.7 times more likely to default treatment, compared with non-substance users $(\mathrm{AOR}=2.73 ;$ 95\% $\mathrm{CI}=1.04-7.15) .{ }^{14}$ Because injection drug users exhibit a high prevalence of chronic viral hepatitis and alcohol abuse, hepatotoxic reactions to anti-TB drugs may be more common. ${ }^{15}$ In a study that examined the role of hepatitis $C$ virus and HIV in anti-TB drug-induced hepatotoxicity, Ungo et $\mathrm{al}^{16}$ found that patients with TB exhibited a fourto-five-fold increased risk of drug-induced hepatitis if coinfected with viral hepatitis or HIV; moreover, they exhibited a 14-fold increased risk if coinfected with both. In addition, efavirenz, nevirapine, and rifampicin may increase methadone clearance, thus causing methadone withdrawal; this may dissuade drug users from continuing treatment. ${ }^{15}$

In a study that examined TB-related mortality in people living with HIV in Eastern Europe and Latin America, a CD4 cell count of $<50 / \mu \mathrm{L}$ was associated with increased TB-related mortality (hazard ratio $=3.46 ; 95 \% \mathrm{CI}=2.02-5.95 ; \mathrm{P}<0.0001$ ) after adjustment for multidrug-resistant TB status. ${ }^{2}$ In another study conducted in Ethiopia, a CD4 cell count of $<75 / \mu \mathrm{L}$ was also associated with increased mortality (adjusted hazard ratio $=4.83 ; 95 \% \mathrm{CI}=1.98$ 11.77). ${ }^{6}$ In our cohort, consistent with the findings from prior studies, patients with HIV-associated TB with a low CD4 cell count $(<50 / \mu \mathrm{L})$ at the time of TB diagnosis had an adjusted hazard ratio of 2.9 (95\% CI=1.1-7.7; $\mathrm{P}=0.03$ ) for mortality at 1 year. The findings from our study and other studies support the recommendation that ART be initiated early during TB treatment in patients with HIV.

Case category other than new cases was associated with increased mortality at 12 months in univariate analysis in our study. However, the association disappeared in the adjusted model. Of note, prior history of TB or retreatment has been associated with increased mortality in some other studies. ${ }^{5,17}$ Because our study was a retrospective case review, it is uncertain whether misclassification or inadequate control for other unknown confounding factors might have obscured an association between case category and mortality.

Studies regarding the association between sputum smear status and death have reported conflicting results. In a retrospective cohort study 


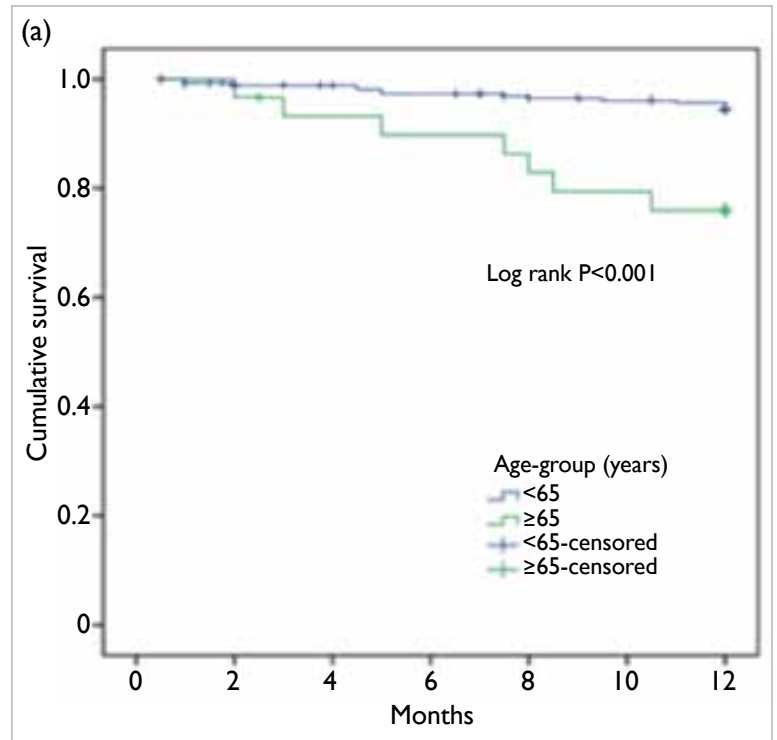

(b)

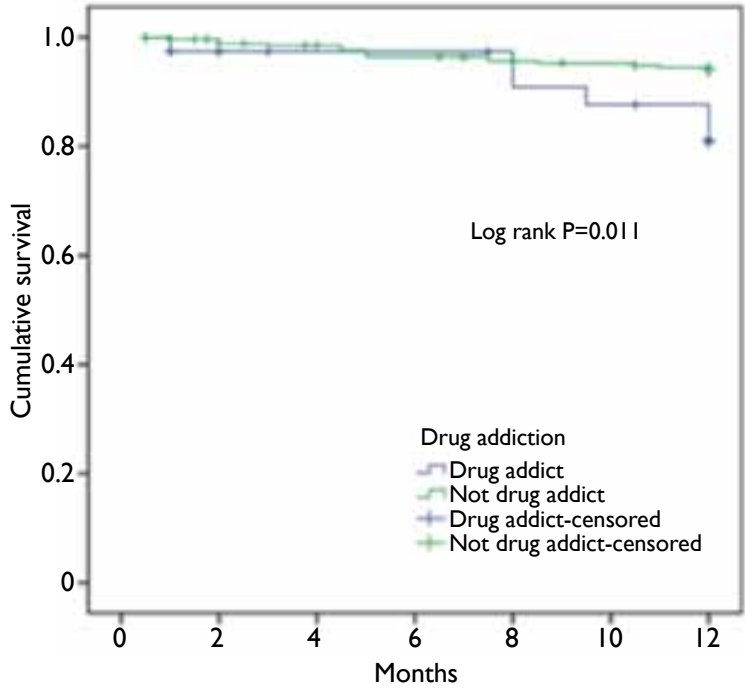

(c)

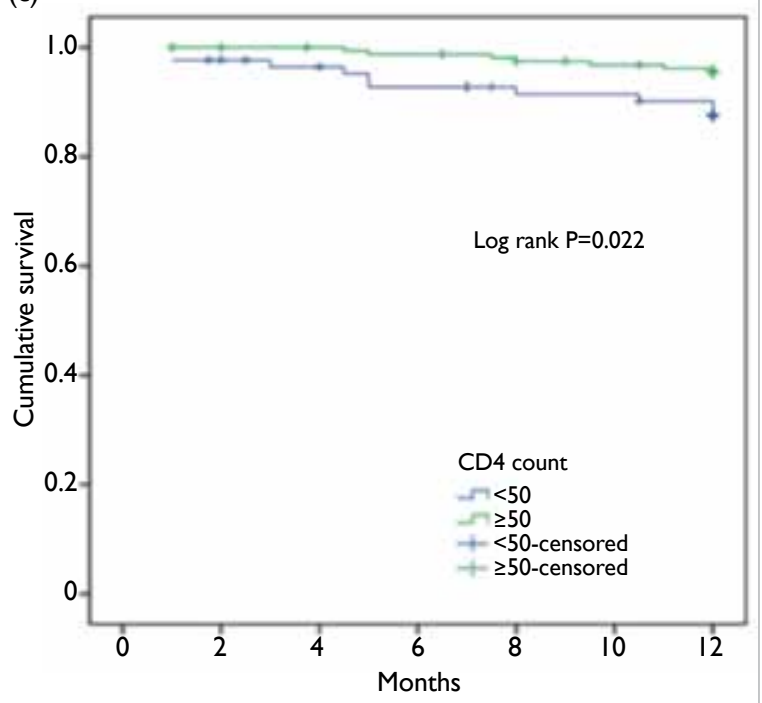

FIG. Kaplan-Meier survival curves of patients with HIVassociated TB at 12 months, stratified for (a) age-group, (b) history of drug addiction, and (c) baseline CD4 cell count Abbreviations: $\mathrm{HIV}=$ human immunodeficiency virus; $\mathrm{TB}=$ tuberculosis of predictors of TB mortality in Khayelitsha, South Africa, an area with high HIV prevalence, no association was found between smear status and death. ${ }^{5}$ Similarly, in a study of patients coinfected with TB and HIV at a teaching hospital in Ghana, no differences were reported in clinical outcome between patients with smear-negative $\mathrm{TB}$ status and those with smear-positive TB status. ${ }^{18}$ In a prospective study of 827 adult TB in-patients registered at Zomba Hospital, Malawi, of whom 77\% were HIV-seropositive, patients with smearnegative pulmonary TB exhibited the highest death rates during 32 months of follow-up (hazard ratio $=2.7 ; 95 \% \mathrm{CI}=2.1-3.5 ; \mathrm{P}<0.001$, compared to smear-positive patients). ${ }^{19}$ Similar findings were reported in studies of patients with HIV-associated TB in South Africa and in Cameroon. ${ }^{17,20}$ Conversely, in a study that examined patients with HIV with culture-confirmed pulmonary TB in the US from 1993 to 2006, patients with smear-negative TB exhibited better survival than patients with smearpositive disease, both before (hazard ratio $=0.82$; 95\% $\mathrm{CI}=0.75-0.90$ ) and after (hazard ratio $=0.81$; 95\% CI=0.71-0.92) the introduction of combination ART. ${ }^{21}$ In our study, a positive sputum smear was associated with mortality in univariate analysis, but not in multivariate analysis. The results from our study regarding the effect of AFB smear status on survival were similar to those from the study in the US. The reasons for observed differences in survival among patients with HIV with sputum smearnegative TB between resource-rich and resourcelimited settings are likely complex; these might have been a result of differences in study populations, the availability of diagnostics, misdiagnosis, or differences in treatment regimens. ${ }^{21}$

Of note, ART was not a prognostic factor for mortality in our study, either for the entire cohort or when the analysis was restricted to the subgroup with a CD4 cell count of $<50 / \mu \mathrm{L}$ (results for the latter not shown). In addition, the mortality rate among patients in the later cohort (2011 to 2015) remained similar compared to the earlier cohort (2006 to 2010), although the proportion of patients receiving ART at 8 weeks had doubled. This conflicts with the finding that ART reduces mortality, reported in some other studies. ${ }^{3,5}$ The failure of ART to affect mortality in our study might have been because ART was selectively initiated for patients with more advanced HIVassociated TB (ie, by attending physicians) during the study period. High age-related mortality in the cohort, as discussed above, and inadequate control for other confounding factors might have masked the protective effect of ART.

The strength of this study is that it included a relatively complete set of data regarding clinical features of all patients, as well as the cause(s) and timing of death among patients who died. Such 
data have been less frequently reported in previous studies. The primary limitation is that it was a retrospective study conducted under programme conditions. Our risk factor evaluation was limited by the availability of data present in the database of the TB-HIV Registry and in clinical records. Information regarding case categories, drug addiction, and CD4 cell count was unavailable for a small subset of patients. Classifying patients with missing case category information as new cases and those with missing substance use data as non-users might have biased our analyses of these risk factors such that no significant differences were found. The time lag between HIV diagnosis and initiation of ART could not be determined because information regarding the date of HIV diagnosis was missing for some patients in the earlier portion of the study period, as well as for patients who were diagnosed outside Hong Kong. Furthermore, information regarding the time lag between presentation of patients to the health care system and the initiation of anti-TB treatment was not captured in the TB-HIV Registry. Therefore, the potential effect of such delay in the initiation of anti-TB treatment on mortality could not be examined. Another limitation is that the accuracy of the data in the programme record forms (on which the database was constructed) and death certificates for coding TB as the underlying cause of death was unknown. Nonetheless, for those patients who died, relevant clinical records from chest clinics and hospitals were traced for review. Misclassification regarding the cause(s) of death should be minimal. Finally, the small number of patients who died, limited statistical power, and inadequate controls for other unknown confounding factors may have concealed the effects of significant variables, as discussed above.

Notwithstanding the aforementioned limitations, we demonstrated that older age, history of drug addiction, and low CD4 cell count $(<50 / \mu \mathrm{L})$ at TB diagnosis were independent risk factors for death within 12 months. This study complements previous studies by providing information regarding risk factors associated with mortality among patients with HIV-associated TB in an area in the Western Pacific region with intermediate TB burden and low HIV prevalence. The results from our study may have important implications for health care programmes; they may aid in formulating innovative strategies and new guidelines to guide targeted measures for the management of disease among subgroups of patients at risk of death from TB or HIV during the course of anti-TB treatment. As such, they may help optimise TB and HIV management in the Western Pacific region.

\section{Author contributions}

Concept or design of study: CK Chan, ECC Leung, CC Leung,
KH Wong.

Acquisition of data: CK Chan, IKY Mak, WK Chan, KCW Chan, MP Lee.

Analysis or interpretation of data: ECC Leung, CC Leung, CK Chan, MP Lee, KCW Chan, IKY Mak.

Drafting of the article: CK Chan, ECC Leung.

Critical revision for important intellectual content: All authors.

\section{Acknowledgement}

The authors would like to thank Dr CM Tam, previous Consultant Chest Physician in-charge of Tuberculosis and Chest Service, Centre for Health Protection, Department of Health of Hong Kong, for his contributions to the conception and design of this work, as well as his valuable comments on the early draft of this article.

\section{Declaration}

All authors have disclosed no conflicts of interest. All authors had full access to the data, contributed to the study, approved the final version for publication, and take responsibility for its accuracy and integrity. The findings of this study were presented in part at the 13th Hong Kong, Macau, Taiwan, Shanghai and Guangdong Tuberculosis Conference, Hong Kong, 2 November 2017.

\section{Funding/support}

This research received no specific grant from any funding agency in the public, commercial, or not-for-profit sectors.

\section{Ethical approval}

This study was approved by the Ethics Committee of the Department of Health of Hong Kong.

\section{References}

1. World Health Organization. Global Tuberculosis Report 2017. Geneva: World Health Organization; 2017.

2. Podlekareva DN, Efsen AM, Schultze A, et al. Tuberculosisrelated mortality in people living with HIV in Europe and Latin America: an international cohort study. Lancet HIV 2016;3:e120-31.

3. TB:HIV Study Writing Group. One-year mortality of HIVpositive patients treated for rifampicin- and isoniazidsusceptible tuberculosis in Eastern Europe, Western Europe, and Latin America. AIDS 2017;31:375-84.

4. Heunis JC, Kigozi NG, Chikobvu P, Botha S, van Rensburg HD. Risk factors for mortality in TB patients: a 10-year electronic record review in a South African province. BMC Public Health 2017;17:38.

5. Pepper DJ, Schomaker M, Wilkinson RJ, de Azevedo V, Maartens G. Independent predictors of tuberculosis mortality in a high HIV prevalence setting: a retrospective cohort study. AIDS Res Ther 2015;12:35.

6. Sileshi B, Deyessa N, Girma B, Melese M, Suarez P. Predictors of mortality among TB-HIV co-infected patients being treated for tuberculosis in Northwest Ethiopia: a retrospective cohort study. BMC Infect Dis 2013;13:297.

7. Cain KP, Anekthananon T, Burapat C, et al. Causes of death in HIV-infected persons who have tuberculosis, Thailand. Emerg Infect Dis 2009;15:258-64.

8. Marcy O, Laureillard D, Madec Y, et al. Causes and determinants of mortality in HIV-infected adults with 
tuberculosis: an analysis from the CAMELIA ANRS 1295-CIPRA KH001 randomized trial. Clin Infect Dis 2014;59:435-45.

9. Tuberculosis and Chest Service, Centre for Health Protection, Department of Health, Hong Kong SAR Government. Annual Report 2015. Available from: http:// www.info.gov.hk/tb_chest/doc/Annual_Report_2015.pdf. Accessed 18 Sep 2018.

10. Special Preventive Programme, Centre for Health Protection, Department of Health, Hong Kong SAR Government. HIV surveillance report-2015 update. Available from: http://www.info.gov.hk/aids/english/ surveillance/sur_report/hiv15.pdf. Accessed 18 Sep 2018.

11. Chan CK, Wong KH, Leung CC, et al. Treatment outcomes after early initiation of antiretroviral therapy for human immunodeficiency virus-associated tuberculosis. Hong Kong Med J 2013;19:474-83.

12. Waitt CJ, Squire SB. A systematic review of risk factors for death in adults during and after tuberculosis treatment. Int J Tuberc Lung Dis 2011;15:871-85.

13. Deiss RG, Rodwell TC, Garfein RS. Tuberculosis and illicit drug use: review and update. Clin Infect Dis 2009;48:72-82.

14. Dooley KE, Lahlou O, Ghali I, et al. Risk factors for tuberculosis treatment failure, default, or relapse and outcomes of retreatment in Morocco. BMC Public Health 2011;11:140.

15. World Health Organization. Integrating collaborative TB and HIV services within a comprehensive package of care for people who inject drugs. Geneva: World Health Organization; 2016.

16. Ungo JR, Jones D, Ashkin D, et al. Antituberculosis druginduced hepatotoxicity. The role of hepatitis $C$ virus and the human immunodeficiency virus. Am J Respir Crit Care Med 1998;157:1871-6.

17. Mabunda TE, Ramalivhana NJ, Dambisya YM. Mortality associated with tuberculosis/HIV co-infection among patients on TB treatment in the Limpopo province, South Africa. Afr Health Sci 2014;14:849-54.

18. Mudd J, Jaramillo L, Kwara E, et al. Impact of smearnegative results on tuberculosis outcome in HIV coinfected patients at a teaching hospital in Ghana. Ann Glob Health 2016;82:516.

19. Kang'ombe C, Harries AD, Banda H, et al. High mortality rates in tuberculosis patients in Zomba Hospital, Malawi, during 32 months of follow-up. Trans R Soc Trop Med Hyg 2000;94:305-9.

20. Djouma FN, Noubom M, Ngomba AV, Donfack $H$, Kouomboua PS, Saah MA. Determinants of death among tuberculosis patients in a semi urban diagnostic and treatment centre of Bafoussam, West Cameroon: a retrospective case-control study. Pan Afr Med J 2015;22:253.

21. Cavanaugh JS, Shah NS, Cain KP, Winston CA. Survival among patients with HIV infection and smear-negative pulmonary tuberculosis-United States, 1993-2006. PLoS One 2012;7:e47855. 